\title{
Global Self-Sufficiency Network-A Collaborative Approach for Addressing Post-COVID-19 Challenges
}

\author{
Mohamed Buheji \\ International Inspiration Economy Project \\ E-mail: buhejim@gmail.com
}

Ana Vovk Korže

E-mail: ana.vovk@um.si

Sajeda Eidan

Reproductive Physiology and Artificial Insemination College of Agricultural Engineering Sciences, University of Baghdad, Iraq E-mail: sajedaeidan2006@gmail.com

Talal Abdulkareem

Reproductive Physiology and Artificial Insemination College of Agricultural Engineering Sciences, University of Baghdad, Iraq E-mail: drtalalabdulkareem2013@gmail.com

\author{
Nikolay Perepelkin \\ E-mail: nikolay@yesevent.ru \\ Bartola Mavric \\ E-mail: mavricbartola@gmail.com
}

Jiri Preis

Department of Geography, Faculty of Economics, University of West Bohemia, Czekh 
E-mail: jpreis@kge.zcu.cz

\author{
Mirjana Bartula \\ E-mail: mirjana.bartula@futura.edu.rs \\ Dunya Ahmed \\ International Inspiration Economy Project, Bahrain \\ E-mail: dr.dunya@ hotmail.com
}

Aisha Buheji

Researcher, Bahrain

E-mail: aisha.buheji1@gmail.com

Tulika Chetiayein

Cultural Stories Writer \& Activist, India

E-mail: tulikachetiayein@gmail.com

Yousef Awad

NGO Leader, Palestine

E-mail: yousefawad2002@yahoo.com

Godfred Beka

University for Development Studies

Social Science, Political and Historical Studies Department, Wa, Ghana

E-mail: bekagodfred@gmail.com

Paul Kakoty

E-mail: kakotypaul3@gmail.com 
Rimli Das

College of History, University Of Delhi, India

E-mail: rimlidas2000@gmail.com

Received: June 4, 2020 Accepted: June 6, 2020 Published: June 9, 2020

doi:10.5296/ber.v10i2.17158

URL: https://doi.org/10.5296/ber.v10i2.17158

\begin{abstract}
COVID-19 raised lots of issues relevant to the status, the readiness and the capacity of the self-sufficiency of the different communities and countries during conditions of lockdown and requirements for social distancing, during the first four months of the pandemic.

An international multidiscipline scholars discussion on zoom, a multi-media conferencing app, is categorised according to the subjects of the self-sufficiency practices that are reflections of the specific attitudes and behaviours that shape the social demands during the COVID-19 pandemic. The scholars discuss the requirements of re-building the self-sufficiency social beliefs which the capital economy destroyed. Based on the methodology of discussion from the different background scholar, the challenges and then the outcome of self-sufficiency projects are defined.
\end{abstract}

Keywords: COVID-19, Self-Sufficiency, Resilient Communities, Lockdown, Multidisciplinary Solutions, Post-COVID-19 Challenges

\title{
1. Introduction
}

COVID-19 made many communities appreciate the importance of self-sufficiency (SF), be it general domestic supplies, or safety supplies, or food supplies. The FAO (2020) accounts for at least 5.3 million African might face hunger in Burkina Faso, Mali and Niger by August 2020. Therefore, proactive local governments as the Kerala Estate in India, started converting wastelands for farming, promoting kitchen gardening, boosting animal husbandry and fisheries among state's action plan to become food secure. Many SF projects have taken place to help meet the sudden demands for health and safety supplies. For example, one project started converting the surplus rice stocks to ethanol for making hand sanitizers to meet the local demands. Kinnunen et al. (2020).

In this paper, we the challenges towards establishing self-sufficiency programs today are discussed. Then the authors discuss the ways to overcome such challenges now. The learning and the unlearning from specific self-sufficiency best practices are explored. Then, the multidiscipline scholars discuss how the SF practices are related to specific attitudes and behaviours which influence the SF economies. The paper also gives the type of social demands that the COVID-19 brought that pushed towards the importance of SF. The scholars discuss the requirements of re-building the social beliefs which the capital economy destroyed. The 
attitudes of stacking items during the pandemic, are given as an example and are discussed to reflect the type of the people mindset today.

Based on the methodology of discussion from the international multidiscipline scholars, the challenges and then the outcome of SF projects are defined. The most suitable projects to start in the new normal are selected. The role of the self-sufficiency in hunger alleviation, or in eliminating under-nourishment is explained. Then how the SF could be a proper resilient economy tool today, in the aftermath of the COVID-19 is discussed further. The scholars here discuss how SF could help in mitigating the downfall of the economies on the head of the weakest section of the society. Another scholar would see how the SF could be an important factor for differentiating any country comparative advantage, especially in the coming new normal. The researchers also exploit what the scholars propose for capitalising on the insecure feelings of the COVID-19 pandemic to bring more SF driven generations. One of the scholars suggests that the outcome of SF could be in scenarios similar to the four-millennium ecosystem foresight framework.

The other macro-outcome of SF projects as per the multidiscipline scholars is its capacity to build a sustainable, resilient society. This is due to the SF could be first like an overhaul for the new normal economic systems where it could help to better build SF approaches that would enhance the sustainable development in different underdeveloped communities, taking certain African communities as an example.

In order to optimise the outcome of the SF projects, some scholars call for using the mindset of inspiration economy in selecting and balance between the materialistic and intellectual element. Part of creating a sustainable, resilient community the scholars call for sustainable food security with an example of some projects carried in the Arab world.

The scholars call in the end for a strong international multidisciplinary Self-Sufficiency Network (SFN) and define the goals of this network based on the findings of this paper. The paper concludes with how the SFN could address the gaps in self-sufficiency today and would a practical action plan that would lead to building better social cohesion during pandemics.

\section{Literature Review}

\subsection{Understanding the Challenges towards Self-Sufficiency Today}

Nikolay Perepelkin is a professor from Moscow, Russia, who sees that self-sufficiency can be seen from two perspectives: the materialist meaning, and the psychological mindset meaning, Taylor (2013). The materialist basis for self-sufficiency is related to life support and food security issues, especially, when common relations and supply chains are destroyed by the challenges of the world; like a pandemic, or natural disasters, or wars. Here, self-sufficiency is beyond food, and it includes sustenance of medical and technical services, and besides general livelihood issues. The main question as Professor Perepelkin put it is "How to physically survive this new condition?" But another side of the problem lays in the question "Are the world ready for self-sufficiency?" because it needs a certain way of thinking and mindset. 
Perepelkin sees that general motivation theory, as Maslow's theory, could help to understand this dual edge position. Putting projects and networks for self-sufficiency now would help to approach sustainable development effectively and would establish closed systems with less dependency on external factors, in cases of emergency. However, it would be very challenging to develop a new strategic and responsible mindset that believes in such an approach. Especially where people have been living lots of ecological challenges due to the competition of making fast earning and return on investment through the overuse of the land and the natural resources. Taylor (2013).

The real problem, as per Professor Perepelkin, right now, is that most of the people are driven by extreme consumerism and unlimited consumption habits. Hence, the provision of an international self-sufficiency network should put priority for shifting self-satisfaction from the drive to buying and owning stuff to fulfil specific impressions to self-sufficiency to satisfy both life and livelihood. This would shift the happiness meanings in our mindsets from consumer to producer and would address many concerns about feeling insecure.

As a result of not believing and practising self-sufficiency, we can see still and even during pandemics disturbing life practices and values, where up to $60 \%$ of refrigerated items in the developed countries are thrown away, while on the other hand, many under-developed countries and even regions in developed economies are suffering from lack of food and water. This unbalanced world is causing the abuse of natural resources together with a meaningless increase of the living standards, besides living standards equality gap.

\subsection{Learning and Unlearning Specific Behaviors for More SF Economies}

Aisha Buheji, is a Bahraini 'Behavioural Economics' researcher who believes that SF is a broad term that can be applied from a personal development level and up to country's strategic planning level. It is about securing and ensuring that one's needs and wants are available in a short reach.

The energy market historically has been a good example of self-sufficiency and its effects on geopolitics. Some countries opted for a model for their energy mix where they can mitigate risks of supply shortages from some conflict-affected regions. However, it is worth noting that energy resources-rich countries also diversified their energy mix to reduce the risk of uncertainties in the market. The exception in policymaking and approach in the United States looks into this matter from a self-sufficiency point of view. What is considered energy security in the majority of countries around the world is energy dependency in the United States. The unique set up of the capital economy and the American industry, specifically in the energy markets, pushes the United States to prioritise self-sufficiency in the oil and gas market. Aisha sees that such an approach is a good example of building a country or even community confidence in the supply chain by building its immune from geopolitical effects.

The behavioural economics researcher Aisha Buheji sees the impact of SF on a macroeconomic level is also evident and important. In modern history, businesses were usually prone to be dependent on longer supplies chains to cut costs. This approach usually works well, and marginally increases profitability. However, in times of crisis as the 
COVID-19 pandemic, longer supply chains prove to bring downturn to businesses. Hence, SF brings in new approaches that need to be taken by many businesses, as learning from COVID-19, where local and sustainable sourcing needs to be established to ensure socio-economic stability. Hintze (2020).

In this post-COVID-19 era, where the economies have got their shock; Aisha believes that SF could be a healing solution. The effect of lockdowns around the world, and the banning of flights, brought light to the fragility of non-self-sufficient markets. "The collapse in some markets and shortages of supplies has highlighted the importance of SF. Countries started to set up medical supply factories, and businesses started to source locally", Aisha says. In this post-COVID-19 era "the new normal" it is essential to have an agile economy. A country should be self-sufficient in its resources, agile in its policymaking, and effective to sustain livelihood and economic growth. Hintze (2020).

\subsection{Pandemic Social Demands for Self-sufficiency}

Self-sufficiency has always been a concern for all human beings all around throughout ages and time, Dr Dunya Ahmed says, a sociologist from the University of Bahrain. Actually, SF is a pillar in any advancement or development, and the needs for it always increases even more in time of crises. However, SF got more complicated during times of fierce pandemics, as the Covid-19, where the total global, regional and local lockdowns overlapped for a period of more than three weeks all over the world. In this time, not only countries and communities were thinking of SF, but even individuals on the level of each household.

Socially, there are lots of lessons learned for better SF policies and people management during the first five months of the pandemic. For example, the obsession for stacking-up many items in houses, despite the countries reassurance of their citizens needs to be studied, is it due to wrong policy approaches, or due to the limited education of the public about the SF for specific items.

\subsection{SF and Attitudes of Stacking During Pandemic}

The attitude of stacking up started from top officials till the normal citizen. The uncertainty and ambiguity show our real social attitudes during times of crisis say Dr Dunya. Many families went into the attitude of stacking-up many things in their basement homes. This stretched the supply chain in many countries, and made many people with less money vulnerable of not affording to buy due to the rise in prices or shortage of items.

Losing the understanding of capacity vs demand, a formula of inspiration economy, which is also could be used a lot in SF, made many communities in fuzziness about their own local strengths. In order to raise the capacity of any community, Dr Dunya emphasis, we need to look into their intrinsic power and also their attitudes. Optimising the capacity within each community, in the long run, can reduce the side effects that happened during the COVID-19 and minimise the negative attitudes that are enhanced as a result of fear, un-confidence and selfishness.

To develop the attitudes of the community, Dr Dunya suggests what Sofo and Sofo (2020) 
recommends about home food gardening as one of the untapped potential opportunities during the pandemic and as healing for new ways of living and development of human behaviour.

The attitude of stacking up started from top officials till the normal citizen. The uncertainty and ambiguity show our real social attitudes during times of crisis say Dr Dunya. Many families went into the attitude of stacking-up many things in their basement homes. This stretched the supply chain in many countries, and made many people with less money vulnerable of not affording to buy due to the rise in prices or shortage of items.

\subsection{SF and the Requirements of Building the Social Beliefs}

Dr Dunya sees that a study by Sims and Grigsby (2019) also shows the link between SF and the social believes. Hence, one needs to work on the (believes) if we want to increase SF in time of crises. The study of Uddin (2020) emphasis the earlier studies of SF need to be revisited after the COVID-19 pandemic as the conditions the whole globe had to go through might not be foresighted. Dr Dunya mentions the example of the emphasis of certain countries in importing grade one or first-class vegetables and fruits, during the time of the pandemic was the unwise decision and showed the miss understanding of the SF in the supply chain where many countries could not export due to lockdown. This emphasis raised the food, besides created a shortage of specific items in the market. (Guo and Tanaka, 2019).

Losing the understanding of capacity vs demand, a formula of inspiration economy, which is also could be used a lot in SF, made many communities in fuzziness about their own local strengths. In order to raise the capacity of any community, Dr Dunya emphasis, we need to look into their intrinsic power and also their attitudes. Optimising the capacity within each community, in the long run, can reduce the side effects that happened during the COVID-19 and minimise the negative attitudes that are enhanced as a result of fear, un-confidence and selfishness.

Dr Dunya sees that a study by Sims and Grigsby (2019) also shows the link between SF and the social believes. Hence, one needs to work on the (believes) if we want to increase SF in time of crises. The study of Uddin (2020) emphasis the earlier studies of SF need to be revisited after the COVID-19 pandemic as the conditions the whole globe had to go through might not be foresighted. Dr Dunya mentions the example of the emphasis of certain countries in importing grade one or first-class vegetables and fruits, during the time of the pandemic was an unwise decision and showed the miss understanding of the SF in the supply chain where many countries could not export due to lockdown. This emphasis raised the food, besides created a shortage of specific items in the market. (Guo and Tanaka, 2019).

\subsection{Learning from Self-Sufficiency Best Practices}

Professor Sajeda mentions successful examples of self-sufficiency as the Dairy Cattle Station in Texas, USA, where the owners use the thousand Holstein cows to collect animal wastes in tanks for the purpose of generating energy from them. Likewise, these animal wastes are used to fertilise the farmer land, and the extra is sold for better economic return. Alternatively, it works as a filter for the water used for washing the barns and watering of the lands cultivated 
with fodder crops, in addition to the cultivating of vegetables and fruits.

Another example mentioned by Professor Sajeda is about a young owner who has more than 3000 heads of dairy cows, and due to bad economic conditions and climate changes, he reduced the herd from three thousand to one hundred dairy cows and built a small dairy plant in his station to sell various types of cheese with a good reputation.

\section{Methodology}

More 40 international multidiscipline scientists and scholars discuss how the SF practices are related to specific attitudes and behaviours which influence the SF economies. The emphasis of the scholars for re-building the social beliefs which the capital economy destroyed and ended up in experiencing repeated selfish attitudes as the stacking items during the pandemics, or emergency situation leads to the proposition of a specialised SF network called SFN.

Based on the methodology of discussion from the international multidiscipline scholars, the challenges and then the outcome of SF projects are defined. The most suitable projects to start in the new normal are selected. The role of the self-sufficiency in hunger alleviation, or in eliminating under-nourishment is explained. Then, how the SF could build a resilient economy today, in the aftermath of the COVID-19, is further explored with the mindset of SFN.

The SFN in the paper represents the methodology for alignment of the holistic perspectives from the different disciplines about a broad subject that is 'self-sufficiency'. The meeting for the establishment for the 'self-sufficiency network' post the outbreak of the COVID-19 pandemic targets to address one research question: How can we optimise self-sufficiency during pandemics?

\section{Case Study}

\subsection{Expected Outcome of SF Projects}

\subsubsection{Selecting the Most Suitable Projects to Start within the New Normal}

Based on the literature review and inputs of the multidisciplinary SF experts panel, the most challenging step forward in the new normal would stay what defines a project to be of a priority than another? How do we select a project amongst all these bulk of all demanded needs and a variety of SF approaches? Dr Buheji, sees that we need to establish some simple frameworks that can filter opinions and shift the effectiveness of any selection to be based on realised judgments, i.e. a factually based decision making.

In order to select the SF project effectively, we need to plot the proposed SF against the two-dimensional scale of the probability of occurrence of a problem, against the level of the impact of this problem once it occurs. The more the project is plotted in the strong area, i.e. the area where the probability and level of the impact of the problem are very high, then this project would the most suitable SF project that would address the need for sustainable, resilient communities as shown in Figure (1). Buheji (2020). 


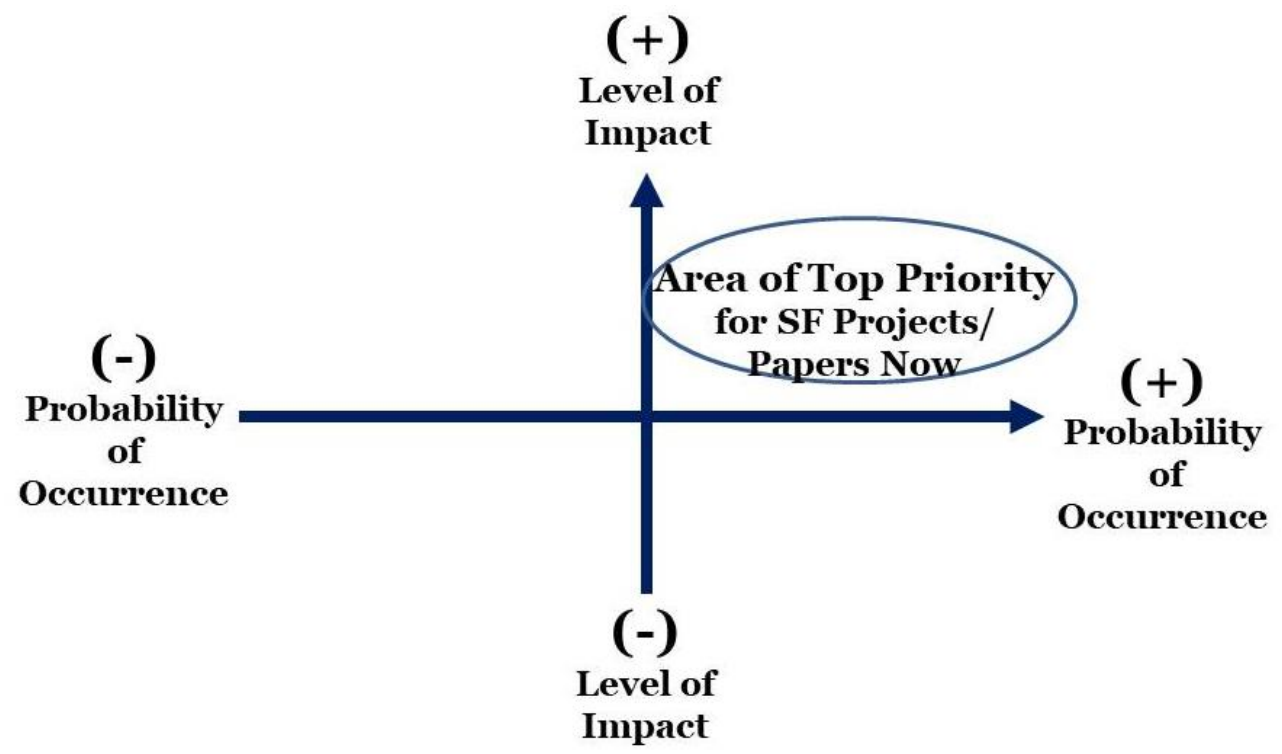

Figure 1. Framework for Selection of Most SF Suitable Project

Specifying the Type of Approach as per the SF Status or Community Condition

Let us argue that the problem of a high probability of occurrence and high level of impact would be that the community suffers turbulence on continuity of wheat, which is an essential meals item for the specified community, then next we need to reword the problem, as to say 'how can we address the shortage and build SF in wheat, with minimal resources?'. Them, we can go further towards defining the targeted approach and evaluate, besides design solutions for the community as per their capacity and functionality.

\subsubsection{The Role of Self-Sufficiency in Alleviation of Hunger or Under-Nourishment}

Paul Kakoty is a young SF and inspiration economy activist from Assam-India; he believes youth can take a greater role in creating a difference in their communities. Living even today in $21^{\text {st }}$ century, in a world filled with hunger and malnourishment, as per Paul, make us more committed to the role of SF in creating a difference in the world scenario. Self-sufficiency can prove to be the backbone of development of any community or nation. Strengthening the village economies and building their core through SF projects can help to reduce various problems, including poverty, migration, hunger etc., FAO (1999). Technology has helped us to provide targeted delivery of nutrients to the deficit. Promoting such SF scenarios around the world will save many lives, besides would improve the storage facilities in the villages, using carious techniques like pasteurisation for the preservation of milk and most importantly creating awareness that can help villages to become learning spots for the whole world Hebber (2020).

\subsubsection{SF as a Resilient Economy Tool in the Aftermath of Pandemics}

Rimli Das is another SF youth and inspiration economy believer. She is a student at the University of Delhi where SF means for her a tool which can make an economy or a country 
resilient to the aftermath of pandemics. Today, as per Rimli, when we see human and all the anthropogenic institutions battling for sustenance; novel ideas, the spirit of serving mankind and hope are our only best friends.

This young lady from India believes that SF brings for her amazing insights on how we can cater the needs of the people around the globe and bridge the gap between the privileged and the ones that are not. Producing and strengthening the locals and promoting their products can not only help them become self-sufficient but also will check unemployment which will lead to the reduction of poverty. Rimli sees from the discussion of the different SF scholars that the different countries have similar sets of problems hindering their overall growth. Hence, she believes we need to expand on the idea of redistributing nutrients enriched genetically modified crops from the different countries to cater to malnutrition. 'Being an Indian, I have always believed what Mahatma Gandhi ji said that the soul of India resides in its villages', Rimli says. Thus, the only way forward is to develop the grassroots and open the plethora of opportunities through effective SF programs. Hebber (2020)

4.1.4 SF for Mitigating the Down Fall of the Economies on the Head of the Weakest Section of the Society

Tulika Chetia Yein, a civil activist and a stories writer from Assam in northern India. As a good observer, like the unique story writers, Tulika sees SF that it comes in the right time as the countries, the communities and the organisations are all prone to instability with the continuous shutdown. Abrogation's and deferments of open exercises have definitely decreased shopper spending across nations and brought the speed of spending down. A hypothesis around the downfall of the global economy can be vividly imagined, as per Tulika. The small scale and local business/industries, on the other hand, are also in some greater plight followed by the migrant workers fighting against hunger, free and save movements Hebber (2020).

"To reduce the plight of the weaker section of the society it is necessary to eliminate the financial dependency of the people in general by introducing and paving their ways to SF", Tulika says. Being a citizen of a developing country, this civil activist suggests developing projects, in Assam, for example, near the riverside. She suggests, for example taking a development project in a village near Dikhow, Disang, Dihing, Brahmaputra and Janji rivers which could bring new opportunities for the local rural population and establish a step forward towards SF comprehensive success story. For example, in such villages just improving the capacity of boating would open river attraction spots that can be used for a picnic. Improving also the capacity of traditional boat rides will generate some seasonal employment, as per Tulika. The other important SF project in this area could be the development of sericulture which is very popular for silk production and where most of the villages of Assam work on.

Tulika of the opinion that SF projects could build eco-villages that would start a skill development program that addresses the project's needs. Such a program should be focused on eliminating economic dependence. For example, one could develop skills for make-up youth artists or handloom craft. Tulika even suggests that the Bamboo, crane and jute can 
bring lots of SF opportunities. Villages which have abundance water can go for organic farming which ensures the sustainability of healthy vegetables to the urban markets. The farming in such villages can go further for establishing horticulture where the village would be filled by different kinds of flowers, and would more flower nursery.

Tulika finally warns about the situation of the migrant workers within the same country such as happened in India at the wake of COVID-19 pandemic. Many migrant workers had to leave their respective workplace, and now they are struggling to find new opportunities in their homeland; thus, it is important to generate opportunities for them.

\subsubsection{SF along with Comparative Advantage}

Aisha Buheji sees that since we face limited resources, it is best during "the normal" if each country strategically plans which goods they need to produce internally and be self-sufficient at -such as essential food products and medical supplies- and depend on international trade for less essential products based on the theory of comparative advantage.

While self-sufficiency is important, the need for international trade should not also be ignored, as per Aisha Buheji, as this will only elongate the economic crisis that we are going to face. International trade is vital for every nation and its economic growth. Each country should focus on producing the goods that they have a comparative advantage at and be self-sufficient, and trade with other countries for other products, which in turn benefits each country involved in the trade and promotes economic growth. The traditional focus on international trade shall always remain an integral part of the world economy, but it is certain that the countries and smaller economies are now required to be better prepared and self-sufficient in a wider range of products and industries than pre-COVID-19 pandemic era.

\subsubsection{Capitalising on the COVID-19 Pandemic to Bring in SF Generations}

Changing the behaviour of the population towards a fundamental economic reality is a difficult task. Therefore, Aisha Buheji sees that if we are to promote SF within an economy, it is important for the legislators to bring in effective tools that can stimulate the economy towards self-sufficiency. The youth need to be prepared for a future where they will be playing a vastly different role than what their forefathers played in their youth. The future economy needs people and communities to be agile and smart; it requires a workforce that is unorthodox. It is important that the future generations are inspired by what COVID-19 has brought the world economy and how to mitigate its negative effects, SF is one clear mitigation.

Aisha Buheji sees that communities need to invest in preparing their generations in learning and practising SF and inspiration economy as they would be the cornerstones for the coming years and foreseen decades for the targeted, agile economy. Shaping future generations realities and making it less prone to economic decline requires realised dedication for SF. The educators and researchers should put more effort into bringing inspiration to the youth and better prepare them for a future economy full of uncertainties but with agility to keep growing. 


\section{$\Lambda$ Macrothink}

\subsubsection{Building SF Scenarios based on Four Millennium Ecosystem Foresight}

Dr. Mirjana Bartula a Serbian Professor who emphasises the importance of using various 'quantitative models' and 'qualitative analysis' to define the millennium ecosystem that would lead to the development of four scenarios. Dr Mirjana sees that (Cork et al., 2006) set very good scenarios of the plausible world futures, which could be helpful for SF besides ecosystem services, as illustrated in Figure (2).

Mirjana believes that all the four scenarios, 'Global Orchestration', 'Order from Strength', 'Adapting Mosaic', and 'TechnoGarden' presents different future that cannot be predicted, but could be assumed by extrapolation of past and current trends.

Through 'global orchestration' we can be built an SF scenario that depends on globally connected societies that focus on global trade and economic liberalisation and takes a reactive approach to ecosystem problems, but that also takes strong steps to reduce poverty and inequality and to invest in public goods such as infrastructure and education. While for 'order from strength' we can establish SF program that would fit the regionalised and fragmented world, which would be concerned more with the security and protection, and emphasise primarily regional markets. This scenario would give little attention to public goods, and taking a reactive approach to ecosystem problems. Another SF scenario could be driven by the political and economic activities, as per the 'adapting mosaic' model in the Cork et al. (2006) framework. Communities in this model need to develop a strongly proactive approach to the management of ecosystems. World Resources Institute (2005).

The fourth model of the Cork et al. (2006) framework, suggested by Dr Mirjana as an SF scenario, is the 'technogarden' model. This model would focus on using the globally connected world, relying strongly on environmentally sound technology, using highly managed, often engineered, ecosystems that take a proactive approach in an effort to avoid problems.

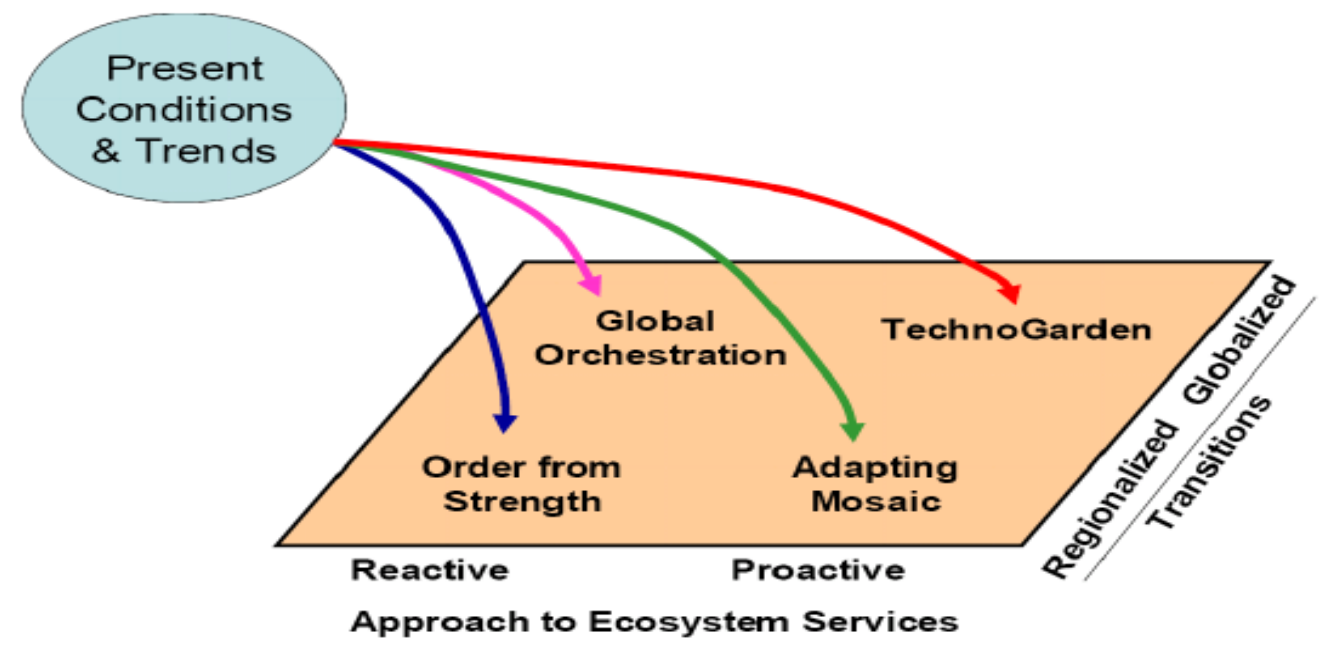

Figure 2. Analogy of SF Four Scenarios, after (Cork et al., 2006) models for Ecosystem Services 


\subsection{SF as a Means for a Sustainable Resilient Society}

\subsubsection{SF as Overhaul for New Normal Economic Systems}

Due to the new normal realities, the investment around the world is pouring inwards towards covering local shortages. This will result in the reduction, of certain foreign direct investments (FDI's). Many countries around the world have been working very hard to grow their economies and placing their bets on FDI's to bring cash flow to the country and stimulate economic growth. With the expected decline in FDI's, SF would be a good tool to overhaul the economic system to be more inwards looking, and more agile. SF brings in more sustainable system that can boost the economic growth in during or even post-COVID-19 pandemic. SF brings in an inwards look, to find resources, and to use the human resources to add-value of what is there. It is important to note that while SF is important, we must not fully ignore the need for international trade, as this will only elongate the economic crisis.

\subsubsection{Better SF Approaches to Enhance Sustainable Development in African Communities}

SF is the state of independence of an organisation or a community, says Godfred Beka a University Student from Northern of Ghana. As an inspiration economy youth leader living in Africa, Godfred focuses on how to fuse SF as part of the efforts for developing poor local communities and as an end to poverty. The beneficiaries will better know how to be independent, knowing how to generate income for themselves. Godfred sees that what (UNHCR, 2005) meant for self-reliance is similar to the target of SF which is to build a strong system in communities through effective social community structure, an increased level of economic activities, as well as it creates great economic links between the communities.

SF is missing today in most of Africa's planning and across all the sectors, as per Godfred. For a community to be self-sufficient, it means they should be able to know "the how-to" of doing things for themselves after they have been rightly thought. Also, it means they will be able to meet their own social and economic needs such as good food, shelter, ability to attend to their health needs and get an education. This can be made possible by capitalising on the resources the country or the community have. Thus, SF can yield good results for communities, if the outcome they can produce their own goods and services from agriculture up to manufacturing. Such SF programs are highly needed in Africa to build the capacity of the people to feed themselves, generate income through trading their produce, and help them pay for life-essential services, such as getting access to good health, good education for their children, and capacity for improving their individual lives and the general community.

Despite many non-profit are working actively in Africa, most of these projects make people more reliant and at the mercies of these organisation, while these organisations also depend on donations to execute their missions. Godfred mentions that some Ghanaian communities have had at least more than 3 NGOs doing projects there with no actual significant progress and still the community is not SF, because this factor was not considered. In countries where unemployment is a huge problem and has many issues of youth migration, especially from rural communities, sustainable development projects as SF are highly needed. 


\subsubsection{SF Projects Using the Mindset of Inspiration Economy}

The main objectives of the SF projects are to establish a long-term sustainable development that would focus on educating communities on the need to be independent, which the focus of inspiration based economies. This is the mindset of inspiration economy which focuses on selective communities, then train them to explore opportunities from their own resources.

Inspiration economy works on first teaching the community the importance of being self-independent and then to identify its unique assets, which might sometimes in the form of values or even raw materials, and which differentiates this community from another one. When raw materials are in the community, it will make the SF project last for long even for the future generation to depend on. On the other hand, the inspiration economy could serve as mediation between the community and the international world, connecting them to the possible right buyers who will be interested in the products being produced. Creating a ready market for the SF project would assure the importance of specific sectors as the agriculture sector. This could start as per Godfred with even selective planting of economic trees in the communities.

If we take the example of the economic trees, there are several trees that would have high return than other trees if planted in the proper place and their yield and distribution improved. For example, the Cashew tree and the moringa tree. Both trees have very good cash return when traded and explored. In Ghana, cashew buts have been one of the cash crops that many families depend on. It attracts buyers mainly from India who comes to buy the raw nuts and export to India to further develop it and supply to companies worldwide. Ghana is one of the top producing cashew countries, but because of the low-profit margin, the benefit of it is not being reflected on the quality of life of its community. There are few local companies that deal with developing cashew nuts. This long-term project will help the community members gain sources of income by selling the raw nuts and latter in the future will learn how to process the nuts for direct consumptions. This will attract buyers all over the country and internationally.

The moringa tree also has huge economic potential right from its leaves to the seeds. The leaves are used for a whole variety of products right from, soap, tea, medicines, shampoo, etc. The moringa seeds contain very rich oil which is of a global demand today. It is used by the massage therapist, used in making facial creams, has great healing and anti-aging properties. The sad news, however, is that, many do not know the value of it and what it does. The process of moringa oil extraction and process the raw cashew nits is not a complex process; for the moringa oil, there are manual equipment and automatic machines used to extract the oil. It is the same for the cashew nuts. A bag of raw cashew cost about 700 Ghana cedis equivalent to about 120 USD. While 1 litre of Moringa oil cost 350 Ghana cedis which is equivalent to about 60 USD. Hence, the profit margin and the potential of quality of life is so important and sustainable.

\subsubsection{SF as a Balance between Materialistic and Intellectual Element}

Professor Perepelkin sees that a self-sufficiency system needs to balance between 
materialistic and intellectual element as shown in Table (1)

Table 1. The Balance need between Materialistic and Intellectual Elements in Self-Sufficient Program

\begin{tabular}{|c|c|c|}
\hline $\begin{array}{l}\text { Element of } \\
\text { self-sufficiency } \\
\text { model }\end{array}$ & Material elements & Intellectual elements \\
\hline Food safety & $\begin{array}{l}\text { - Intensive and scientific } \\
\text { agricultural production (instead the } \\
\text { extensive and traditional way). } \\
\text { - Balanced distribution. }\end{array}$ & $\begin{array}{l}\text { - Learning and understanding } \\
\text { environmental agricultural production. } \\
\text { - Rational consumption and mindful } \\
\text { consumers behavior. }\end{array}$ \\
\hline Health and wellness & $\begin{array}{l}\text { - Sufficient medical help and } \\
\text { technological procuring of healthcare } \\
\text { systems; }\end{array}$ & - Health education and promotion; \\
\hline Social development & - $\quad$ Material support and procuring; & $\begin{array}{l}\text { - Growing and learning of personal and } \\
\text { business social responsibility; } \\
\text { - Growing and learning of understanding } \\
\text { the social and political activity; }\end{array}$ \\
\hline $\begin{array}{l}\text { General } \\
\text { environment } \\
\text { climate }\end{array}$ & $\begin{array}{l}\text { - } \quad \text { New way of production; } \\
\text { - } \quad \text { Preserving of natural resources. }\end{array}$ & $\begin{array}{l}\text { - Growing and learning of personal and } \\
\text { business social responsibility; }\end{array}$ \\
\hline Technology & - Access to the new technologies. & $\begin{array}{l}\text { Technical education and acceptance } \\
\text { (developer and user levels); }\end{array}$ \\
\hline Finance & $\begin{array}{l}\text { - Developing financial system } \\
\text { elements. }\end{array}$ & $\begin{array}{l}\text { - Learning the basics of "financial } \\
\text { literacy" and financial responsibility; }\end{array}$ \\
\hline Education & $\begin{array}{l}\text { - Education organisations general } \\
\text { procuring; } \\
\text { - Preparing teachers and materials } \\
\text { providing. }\end{array}$ & - $\quad$ Promotion need of education ideas \\
\hline Culture & $\begin{array}{l}\text { - Access to the historical and } \\
\text { cultural objects; } \\
\text { - Support of traditional arts. }\end{array}$ & $\begin{array}{l}\text { - Cultural and art education; } \\
\text { - Changing the role models and referent } \\
\text { groups characteristics (stand apart of } \\
\text { luxurious and over-consuming models. }\end{array}$ \\
\hline
\end{tabular}

Professor Perepelkin warns about the resistance to change because most people would prefer to stay in the comfort zone as part of the pattern of rigid human behaviour. However, he believes that this is the right moment for a change for self-sufficiency as the disappointments with the challenges of the COVID-19 pandemic could help to trigger the need for positive changes in the world. These changes could lead us to the harmonic and sustainable society development based on finding the balance between material and intellectual tools. The world needs more rational justification for the proper usage of natural resources through technical solutions and a certain level of mindset supported by generally accepted life values similar to 
self-sufficiency.

\subsubsection{SF as a means for Sustainable Food Security}

In Iraq, Sajeda mentions about a local experience. She says how throughout the years of economic blockade, the Iraqi's faced the problem of food and feed, and this challenge derived many solutions. One of these solutions was the domestic chicken breeding project (5-10 chicken/family). Such local experiences, was very effective for the development of further self-sufficiency programs as the development of agricultural crops, such as wheat and rice, water-resistant with soil salinity.

Professor Sajeda believes that one of the most important areas in the world that need to transform for self-sufficiency after Covid-19 are the communities in the Arab and regional countries. The Iraqi professor sees from her experience that such region need the following self-sufficient strategies and action plans through first working on providing strategic storage for seeds (a bank for storing all types of forage seeds or that are used in human nutrition). Preservation of local animals, as seen by Sajeda should become another priority where the preference should be given to animals resistant to all local conditions, and at the same time working to improve their productive ability through selection, crossing, or benefiting from artificial insemination and embryo transfer techniques for animal conservation.

The third action plan that Professor Sajeda recommended is the protection of the local products by setting a type of tariff for the materials entering the country, so that their prices are higher than the local product, or preventing the importation of specific products that can be provided within countries such as banning the import of poultry meat, sheep, cows and goats. These will motivate owners to breed these animals. The Iraqi expert emphasised that part of self-sufficiency program should be building new animal stations that provide adequate conditions for the animal, with the possibility of benefiting from all of its products, for example, taking advantage of its waste to produce energy and fertiliser, or making use of the sun to provide electrical energy and others.

The last recommendation for effective self-sufficiency that came from Professor Sajeda is about working to take advantage of the vast abandoned lands without interest as natural pastures, or cultivate them with fodder crops, especially in the years when the amount of rain is heavy and then work on storing these fodder crops (hay and Silage) for many years that can be utilised in the event of a shortage of feed. She also emphasised the importance of paying attention to agricultural extension services, such as the building the bridges between the universities and research centres from one side, and the breeders on the other side, working together to find solutions to their different problems and challenges.

Similarly, Professor Talal emphasised the role of agricultural extension specialists in supporting the transfer towards food security self-sufficiency since they teach the owners with technical and education knowledge of how to use the low-prices fodders and treated low-quality fodders with chemical agents will increasing their trust to improve their productivity and maximise the self-sufficiency after the COVID-19 outbreak. 


\subsubsection{SF as a Means for a Sustainable Resilient Society}

Dr Mirjana sees that 'adapting mosaic' model scenario can be the most suitable for the creation of SF and sustainable, resilient society. This is due that in this scenario model, the communities and countries can share the same resources, such as river or lakes, and become more interdependent since they rely on the same resources. This scenario as per Dr Mirjana could be implemented by two-directions: bottom-up and top-down. Buheji (2018).

There are four major steps towards the sustainable, resilient community, as mentioned by Dr Mirjana. First, we need to assess the potential for the SF of the local communities or the country sharing the same resources. For example, the same river or lake. Then, assessment of the current situation would be needed, i.e. what type of pressure on the natural resources, what are the current food production patterns. This can be followed by public opinion assessment on the needs to reach the status of SF community.

Hence, in order to build a sustainable resilient society, we need to design a plan for creating SF local communities that focus on food, energy and water security. These plans also depend on the participation of the local community and should address these communities potentials. Such practices are very similar to the circular economy, which can be the baseline of each SF project. Buheji $(2018,2020)$.

Dr Mirjana emphasises that there are other SF activities that could lead to a sustainable, resilient society as improving the wastewater management through green technologies which can be constructed in small villages. This could bring in more green energy production when supported with growing of energetic agro crops for biomass (energy) production and bioremediation of degraded land.

Other SF project that could help build a sustainable, resilient society is sustainable food production as setting up permaculture. For example, creating green cities or green infrastructure installations, such as green roofs, tree pits and swales - can yield multiple urban benefits. These include reduction of water and air pollution, mitigation of flood risk and heat islands, as well as the provision of areas for recreation and urban agriculture.

SF projects could come to save our societies and thus to move them from a deteriorating situation. Moving from deteriorating to a stable and successful driven society requires that we maintain the balance between (live and livelihood). However, as shown in Figure (3) if we are to move further towards emerging vibrant and sustainable resilient community we need to have agility in spirit and in doing; besides again maintaining the balance between (live and livelihood). Dr Buheji emphasises that it is our choice now of which direction we take from the deteriorating status of our communities today, due to the COVID-19 pandemic. The direction we take would define whether we would stay managing a deteriorating status, or transforming towards a society that could balance between both important choices as (life and livelihood). One of the available and under-utilised vehicles of transformation is self-sufficiency. 


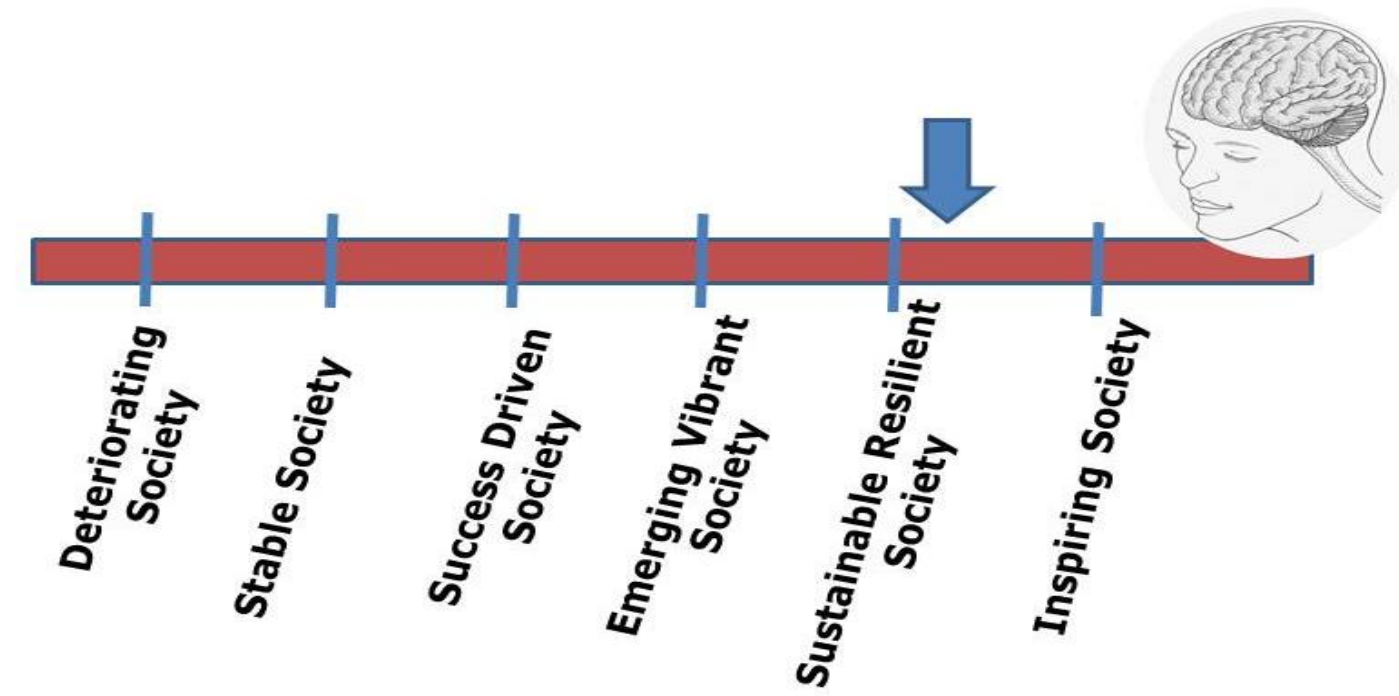

Figure 3. Outcome of Solving Socio-Economic Problems with Minimal Resources

\subsubsection{Resilience to fulfil the needs of the Palestinian Community}

Yousef Awad is an NGO leader that supports the Palestinian community with SF approaches and keep their struggle by improving their capacity to meet some of the quality of life, despite all the Israeli procedures that strain such NGO from delivering its services effectively. The NGO is responsible for fulfilling the local needs from food and other needs. Besides, supporting self-sufficiency practices through the distribution of seeds and plants for each Palestinian family to plant them in their limited spaces and small gardens. Then, these people are encouraged to share their products with the local community. Where possible the NGO encouraged its community to raise even animals such as hens, goats and cows.

This program that started since the eighties helped the local communities to find alternatives that covered their needs in the best way and established a spirit of teamwork to achieve common goals. Yousef sees that SF is an essential tool for any people living under suppression, or being marginalised. The feelings of many members of this community in Palestine give them the sense of having some independence from the closed chains of the occupation and give them a sense of differentiated identity that keep the coming generation committed to the cause of their land Palestine.

\section{Discussion and Conclusion}

\subsection{The Requirements for Establishing a Strong International Multi-Disciplinary Self-sufficiency Network (SFN)}

Professor Jiri Preis, who specialise in Geography Economics, in the Czech Republic, believes that SFN can be strong network since if it is made from the multidisciplinary background from specialists and academics from various parts of the world, which could facilitate to bring in multi-culture circles perspectives and worldviews. However, Jiri believes that this can be both great strengths as well as weakness. However, the strengths outweigh the 
weaknesses since it would help to build stronger understanding and explanations about what happens in countries of the North as well as the South.

Professor Jiri sees that the most important immediate impact of Covid-19 pandemics was and still is food security and the halt of supply chains that occurred since the outbreak, Kinnunen et al. (2020). If a network like SFN can observe and study, how that influenced the people and the communities on global, as well the impact on both the regional and local level, then this could be a good start to an international self-sufficiency network. SFN can also look for the ways and provide ideas, how that can be changed, so that the losers of Covid-19 pandemics can be helped and provided by searching for good/best practices, etc.

Using both Inspiration Economy and Self-Sufficiency as per Professor Jiri would help to be effective learning, and bring the best opportunities of how the different societies will be transformed in the post-corona stage. i.e. How can SFN benefit from the more digitalisation of society, shared economy, conditional income, regionalisation and possible rising protectionism, and socio-economic inequalities, due to the Covid-19? How do the new normal changes will look like, in the North and the South? And how to minimise the impact of the Covid-19, and its severity, in the countries of both the South and North?

\subsection{Goals of Self-sufficiently Network (SFN)}

The main goal of building a self-sufficiency network (SFN) is simply to empower people to be self-sufficient and have their own independent or inter-dependent business models. This means the network works to spread and embed more practices that disseminate responsible lifestyle, where nature would be taken care of, waste would be minimised or re-used, and food and household items would be grown in a sustainable way. The SFN would work on authentically inspiring people and communities about how much they can be self-sufficient and learn by doing, while benefiting from the technology of today, besides the proven knowledge of the ancestors.

\subsection{Do We Have Knowledge For Self-Sufficiency?}

There are quite good experiences of many countries that have managed to re-build lost self-sufficiency programs as Slovenia. Prof Ana Vovk mentions about her to build a teaching reference of excellence farm where teachers and students from Europe and especially Slovenia come and learn the holistic agroecological model she developed over years of learning by doing and scientific research. The model focuses on understanding the local geography, the traditions of the areas, the technology and the ethics, as shown in Figure (1). Korze (2020)

The Ana Vovk model focuses on building the self-sufficiency mindset in the educators, future generations and the decision-makers through focusing as illustrated in Figure 4 on the co-natural production and safe processing where no artificial pesticides are used. Also, the model focus that the farms run by fair trade and community coops and cooperation, which support the sustainability of the local market even in cases of crisis. 


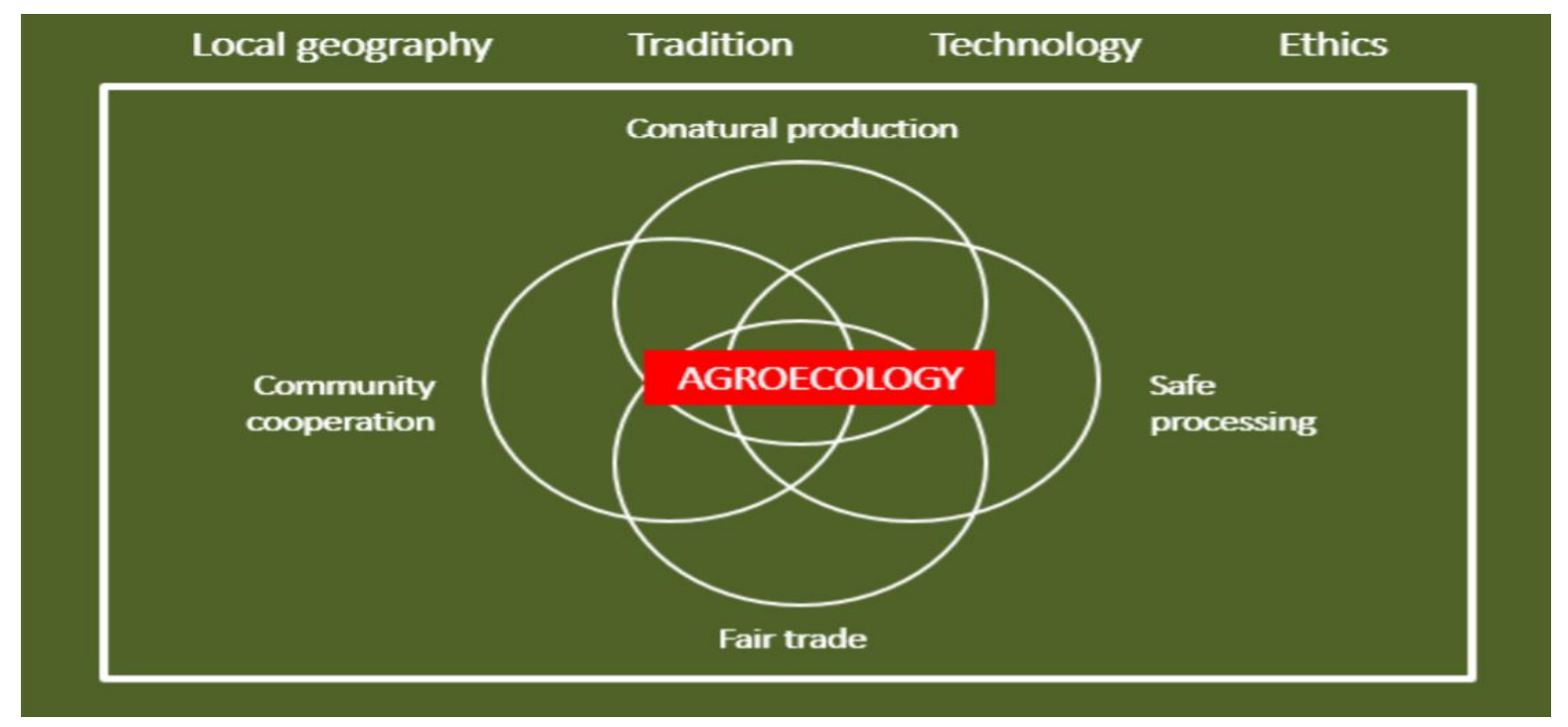

Figure 4. Ana Vovk for Self-Sufficiency

Professor Ana and her team produce food at 1.5 ha; we have even the water and energy are produced and recycled from the farm. Every year this farm teaches thousands of students and youth how to become self-sufficient.

\subsection{SFN Practical Action Plan}

One of the highly needed COVID-19 pandemic demands is the need to collaborate to empower teams to deal with the issue of self-sufficiency as an essential life routine. These plans would be delivered by the support of research, preparation of papers, projects, policies and instructions, preparation of educational courses, and counselling.

The educational programs of SFN targets to establishing value chains that would lead to the improvement and the sustenance of self-sufficiency, as a value in the community. The SFN would deliver self-sufficiency assessment and certification which including assessing on criteria as environmental protection and due diligence, besides the utilisation of clean technologies. SFN also focus that the production is profitable for the family, the village and to improve the livelihood of the people through being exported through the specific value chain.

\subsection{Building Social Cohesion through SFN}

Professor Jiri sees, that local economies are often interconnected with 'social cohesion' of the community. Hence, it is highly recommended that SFN search and look for the best ways of how the social cohesion could be enhanced through evaluating the differences between theme assures that was taken place at different countries, and what was their impact (e.g., stay-at-home orders; lockdown borders; impact on the sector of services, tourism etc.). Hintze (2020).

In order to implement the social cohesion concept, Professor Jiri recommends that the 
international SFN network activities should focus first on data gathering and analysis, based on everyone expertise. Then, these data are published in papers writing through the collective partnership of all the international teams. Then, this should be followed by round-table discussions with local stakeholders, or the problem under-investigation in order to formulate ideas and final recommendations for implementation. The SFN as per Professor Jiri should have a high-quality website that disseminates the network types of activities, ideas, and thus enhance international networking. All the SFN members should be encouraged to share their ideas with their students in the universities/colleges so that these students can also be part of the self-sufficiency movement. Besides; this would give the opportunity to implement further inputs, or results into the university lectures so that to inspire the students to get more engaged in self-sufficiency projects.

\subsection{Final Words}

The implication of this paper is that it calls for channelising the different available resources of the communities during any global pandemic, through identifying first how to convert the resources into practical assets that can be optimised. The conclusion, confirm that self-sufficiency is the surest way to promoting community development and creating a permanent sustainable and resilient resources for all the types of communities. The contribution of the paper comes from its multidisciplinary contributors whom all came to agree on the importance of SF and the establishment of a network (SFN) that would help in making the communities and the world more ready future pandemic and global emergency crisis.

\section{References}

Buheji, M. (2020). Visualising Resilient Communities. AuthorHouse, UK.

Buheji, M. (2018). Understanding the Power of Resilience Economy, An Inter-Disciplinary Perspective to Change the World Attitude to Socio-Economic Crisis. AuthorHouse, UK.

Cork, J., Peterson, G., Bennett, E., Petschel-Held, G., \& Zurek, M. (2006). Storylines of the MA scenarios: a synthesis. Ecology and Society, Ecology and Society, 11(2), 11.

https://doi.org/10.5751/ES-01798-110211

FAO. (2015). Food self-sufficiency and international trade: a false dichotomy? [Online] Available: http://www.fao.org/3/a-i5222e.pdf

FAO. (1999). Food Insecurity: when people must live with hunger and fear starvation. The state of food insecurity in the world. [Online] Available:

http://www.fao.org/NEWS/1999/img/SOFI99-E.PDF

Guo, J., \& Tanaka, T. (2019) Determinants of international price volatility transmissions: the role of self-sufficiency rates in wheat-importing countries. Palgrave Communications, 5(1), 124. https://doi.org/10.1057/s41599-019-0338-2

Hebber, N. (2020). Biggest message from COVID-19 is that India must be self-reliant, says Modi. The Hindu News. [Online] Available: 
https://www.thehindu.com/news/national/biggest-message-from-covid-19-is-that-india-mustbe-self-reliant-says-modi/article31422674.ece

Hintze, M. (2020). How the COVID-19 Crisis Could Spark an Era of Economic Self-Sufficiency, Milken Institute. [Online] Available:

https://milkeninstitute.org/power-of-ideas/how-covid-19-crisis-could-spark-era-economic-self -sufficiency

Kiernan, A. (2020). Why self-sufficiency is the way forward during the Covid-19 crisis, JOE. [Online] Available:

https://www.joe.ie/business/why-self-sufficiency-is-way-forward-during-the-covid-19-crisis696070

Kinnunen, P., Guillaume, J., Taka, M., D’Odorico, P., Siebert, S., Puma, M., Jalava, M., \& Kummu, M. (2020). Local Food Crop Production can Fulfil demand for less than one-third of the Population. https://doi.org/10.1038/s43016-020-0060-7

Sims, A., \& Grigsby, M. (2019). Prepper-Worthy Identity Work: A Cultural Repertoire for Constructing a Secure Self in an Insecure World. Sociological Spectrum, 39(2), 93-115. https://doi.org/10.1080/02732173.2019.1608338

Sofo, A., \& Sofo, A. (2020). Converting Home Spaces into Food Gardens at the Time of Covid-19 Quarantine: all the Benefits of Plants in this Difficult and Unprecedented Period, Human Ecology. https://doi.org/10.1007/s10745-020-00150-8

Taylor, S. (2013). Self-Sufficiency: An Essential Aspect of Well-Being. Self-esteem can be very fragile, unless it's underpinned by self-sufficiency. Psychology Today. [Online] Available:

https://www.psychologytoday.com/us/blog/out-the-darkness/201303/self-sufficiency-essential -aspect-well-being

Uddin, M. M., Akter, A., Khaleduzzaman, A. B. M., \& Sultana, M. N. (2020). Forecasting milk production in Bangladesh toward achieving self-sufficiency. Livestock Research for Rural Development, 32(5).

Korze, A. (2020). Educational Polygon for Self-sufficiency in Senegal (West Africa). International Journal of Inspiration \& Resilience Economy, 3(2), 35-40.

World Resources Institute. (2005). Ecosystems and Human Well-Being, Millennium Ecosystem Assessment. [Online] Available:

https://www.millenniumassessment.org/documents/document.356.aspx.pdf

\section{Copyright Disclaimer}

Copyright for this article is retained by the author(s), with first publication rights granted to the journal.

This is an open-access article distributed under the terms and conditions of the Creative Commons Attribution license (http://creativecommons.org/licenses/by/4.0/). 